\title{
Long-Term Efficacy of Rehabilitation Following Arthroscopic Synovectomy in Patients With Rheumatoid Arthritis Treated With Biologic Agents
}

\author{
Katsuaki Kanbe, $\mathrm{MD}, \mathrm{PhD}^{1,2}$, Chiaki Sekine, $\mathrm{MD}, \mathrm{PhD}^{1,2}$
}

Departments of ${ }^{1}$ Rehabilitation and ${ }^{2}$ Orthopaedic Surgery, Tokyo Women's Medical University, Medical Center East, Tokyo, Japan

\begin{abstract}
Objective To investigate the long-term efficacy of rehabilitation following arthroscopic synovectomy in patients with rheumatoid arthritis treated with biologic agents.

Methods Arthroscopic synovectomy was performed in 29 joints of 17 patients, which were divided into two groups. Group 1 included arthroscopic synovectomy plus rehabilitation for 19 joints in 10 patients, and group 2 included arthroscopic synovectomy without rehabilitation for 10 joints in 7 patients. The Disease Activity Score C-reactive protein (DAS28-CRP), Health Assessment Questionnaire-Disability Index (HAQ-DI), and Functional Independence Measure (FIM) values (motor subscale) at 9.7 years after arthroscopic synovectomy were evaluated to identify the clinical factors related to outcomes.

Results The increase in FIM score was significant in group $1(\mathrm{p}=0.05)$. HAQ-DI at 9 years was significantly decreased in group $1(\mathrm{p}=0.02)$. Therefore, arthroscopic synovectomy with rehabilitation was significant in improving FIM and HAQ-DI scores over a long period. Multiple regression analysis of FIM scores at 9 years indicated that rehabilitation $(\mathrm{p}=0.03)$ and disease duration $(\mathrm{p}=0.02)$ were significantly related to outcomes. FIM score at 9 years was significantly negatively correlated with disease duration $(\mathrm{p}=0.01, \mathrm{r}=-0.58, \mathrm{Y}=88.89-0.21 \mathrm{X})$.

Conclusion Rehabilitation following arthroscopic synovectomy was effective in achieving high FIM scores over time in patients with rheumatoid arthritis.
\end{abstract}

Keywords Rehabilitation, Synovectomy, Rheumatoid arthritis

\section{INTRODUCTION}

Rheumatoid arthritis (RA) is a chronic disease characterized by systemic inflammation and joint destruction that result in the impairment of activities of daily living. Several studies have assessed the benefits of rehabilitation afforded to patients with RA who have persistent or progressive disability [1-7]. Recent advances in pharma-

Received March 8, 2017; Accepted April 25, 2017

Corresponding author: Katsuaki Kanbe

Department of Orthopaedic Surgery, Tokyo Women's Medical University, Medical Center East 2-1-10 Nishiogu, Arakawa, Tokyo, Japan. Tel: +81-33810-2900, Fax: +81-3-3810-9934, E-mail: kambe.katsuaki@twmu.ac.jp

ORCID: Katsuaki Kanbe (http://orcid.org/0000-0002-0703-4938); Chiaki Sekine (http://orcid.org/0000-0003-2064-253X).

(c) This is an open-access article distributed under the terms of the Creative Commons Attribution Non-Commercial License (http://creativecommons.org/ licenses/by-nc/4.0) which permits unrestricted noncommercial use, distribution, and reproduction in any medium, provided the original work is properly cited. Copyright $\odot 2017$ by Korean Academy of Rehabilitation Medicine 
cological care, including tumor necrosis factor (TNF) blockade or interleukin (IL)-6 antagonists, for RA have reduced the consequences of disease activity, radiological damage, and functional disability [8-12]. However, despite using biologic agents, some patients continue to experience swelling and tenderness, thereby resulting in disability. We previously reported that arthroscopic synovectomy reduced the disease activity in RA and facilitated the efficacy in insufficient response to biologics [13]; however, a combined therapy with rehabilitation and arthroscopic synovectomy has not yet been investigated, particularly with respect to long-term outcomes. In this retrospective case-control study, outcomes following arthroscopic synovectomy, with or without rehabilitation, were analyzed in patients over 9 years.

\section{MATERIALS AND METHODS}

Arthroscopic synovectomy was performed in 29 joints of 17 patients, based on the American College of Rheumatology (formerly, the American Rheumatism Association) criteria [14] and categorization by Steinbrocker et al. [15]. Four patients were categorized as having stage II RA, 10 patients were categorized as having stage III RA, and 3 patients were categorized as having stage IV RA. Ten patients were categorized as having class 2 disease and 7 patients were categorized as having class 3 disease, and they had a mean age of $54.82 \pm 9.82$ years, mean disease duration of $9.89 \pm 9.03$ years, mean follow-up period of $9.76 \pm 1.15$ years, mean methotrexate (MTX) dosage of $6.24 \pm 0.97 \mathrm{mg} /$ week, mean predonisolone (PSL) dosage of $4.32 \pm 2.14 \mathrm{mg} /$ day, mean C-reactive protein (CRP) level at baseline of $4.83 \pm 3.68 \mathrm{mg} / \mathrm{dL}$, mean Disease Activity Score (DAS28)-CRP of 5.18 \pm 0.56 , mean Health Assessment Questionnaire-Disability Index (HAQ-DI) [16] of $1.63 \pm 0.79$, and mean Functional Independence Measure (FIM) motor subscale [17] score of 78.65 \pm 4.01 . All patients were treated with biologics, including $3 \mathrm{mg} / \mathrm{kg}$ of infliximab (IFX) in 11 patients, $50 \mathrm{mg} /$ week of etanercept (ETN) in 4 patients, and $8 \mathrm{mg} / \mathrm{kg}$ of tocilizumab (TCZ) in 2 patients. These patients were divided to two groups. Group 1 included 10 patients (80\% females) who underwent arthroscopic synovectomy with rehabilitation for 19 joints (13 knee joints, 4 shoulder joints, 2 wrist joints, and

Table 1. Baseline characteristics of patients who underwent synovectomy with or without rehabilitation for rheumatoid arthritis

\begin{tabular}{|lccc|}
\hline & Rehabilitation (+) & Rehabilitation (-) & p-value \\
\hline Number of patients & $10(19$ joints $)$ & $7(10$ joints $)$ & 0.12 \\
\hline Age (yr) & $51.70 \pm 7.86$ & $59.29 \pm 11.18$ & 0.78 \\
\hline Female (\%) & 80 & 85.7 & 0.37 \\
\hline Disease duration (yr) & $8.18 \pm 10.74$ & $12.33 \pm 5.72$ & 0.56 \\
\hline Follow-up period (yr) & $9.70 \pm 1.25$ & $9.86 \pm 1.07$ & ND \\
\hline Biologic agents & & & \\
\hline IFX & 7 & 4 & ND \\
\hline ETN & 2 & 2 & \\
\hline TCZ & 1 & & \\
\hline Synovectomy & 13 & 3 & \\
\hline Knee & 4 & 2 & 0.75 \\
\hline Shoulder & 1 & 1 & 0.33 \\
\hline Elbow & 2 & $5.12 \pm 0.39$ & 0.86 \\
\hline Wrist & $5.21 \pm 0.68$ & $1.86 \pm 0.53$ & \\
\hline DAS28-CRP at baseline & $1.46 \pm 0.92$ & & \\
\hline HAQ-DI at baseline & $78.80 \pm 3.91$ & & \\
\hline FIM at baseline & & & \\
\hline
\end{tabular}

Values are presented as mean \pm standard deviation or number.

IFX, infliximab; ETN, etanercept; TCZ, tocilizumab; DAS, Disease Activity Score; CRP, C-reactive protein; HAQ-DI, Health Assessment Questionnaire-Disability Index; FIM, Functional Independence Measure. 
1 elbow joint), and they had a mean age of $51.70 \pm 7.86$ years, mean disease duration of $8.18 \pm 10.74$ years, and mean follow-up period of $9.70 \pm 1.25$ years. Seven patients were treated with IFX, 2 patients were treated with ETN, and 1 patient was treated with TCZ. The same biologic treatment was maintained throughout the final follow-up period. Baseline DAS28-CRP was 5.21 \pm 0.68 , HAQ-DI was $1.46 \pm 0.92$, and FIM score was $78.80 \pm 3.91$ (Table 1). Group 2 included 7 patients ( $86 \%$ females) who underwent arthroscopic synovectomy without rehabilitation for 10 joints ( 4 knee joints, 3 shoulder joints, 2 elbow joints, and 1 wrist joint) and they had a mean age of $59.29 \pm 11.18$ years, mean disease duration of $12.33 \pm 5.72$ years, and mean follow up-period of $9.86 \pm 1.07$ years. Four patients were treated with IFX, 2 patients were treated with ETN, and 1 patient was treated with TCZ. The same biologic treatment was continued throughout the final follow-up period. Baseline DAS28-CRP was 5.12 \pm 0.39 , HAQ-DI was $1.86 \pm 0.53$, and FIM score was $78.43 \pm 4.47$. We used a 4.0 $\mathrm{mm}$ arthroscope (Smith \& Nephew Inc., London, UK) for the knee and the shoulder joints and a $2.7-\mathrm{mm}$ arthroscope (Smith \& Nephew Inc.) for the ankle joints. We also used a shaver apparatus (Smith \& Nephew Inc.) and VAPR (Johnson \& Johnson Inc., New Brunswick, NJ, USA) to remove the synovium during arthroscopic synovectomy, as previously reported [13]. Baseline DAS28-CRP was 5.12, HAQ-DI was 1.86, and FIM was 78.43. DAS28-CRP, FIM, change in DAS28-CRP, and change in FIM at the time of the final observation at 9.7 years, on average, after arthroscopic synovectomy were evaluated and analyzed to identify the clinical factors related to patient outcomes.

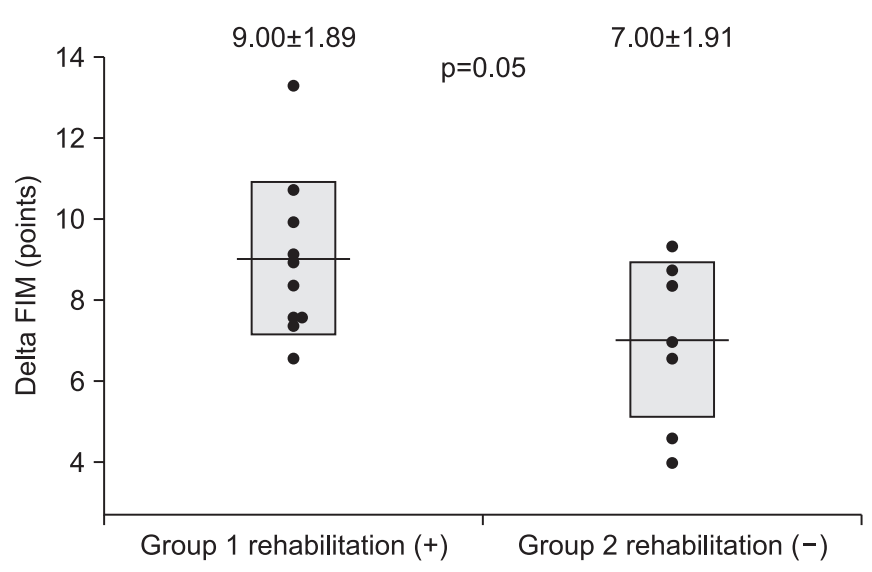

Fig. 1. Change in Functional Independence Measure (FIM) after arthroscopic synovectomy with (group 1) or without (group 2) rehabilitation after 9 years.
Informed consent was obtained from all patients, and the study protocol was approved by the ethics committee of Tokyo Women's Medical University (Approval No. 1321).

\section{Rehabilitation protocol}

One day after arthroscopic synovectomy in RA patients, passive range of motion (ROM) exercise was permitted, while assisted active ROM exercise was allowed 1 week after the operation in a rehabilitation room for outpatients. Active ROM exercise was commenced 2 weeks after the operation, but it needs to be clarified whether it means 2 weeks or 4 weeks postoperatively. An exercise program of two times a week for 12 weeks was applied for rehabilitation after synovectomy. The level of rehabilitation was determined by the sites of different joints and the severity of joint destruction, as assessed by the surgeon. Activities of daily living were restored after 12 weeks of rehabilitation; however, if RA disease-related activity or inflammation increased, rehabilitation was discontinued for a short period until the general condition had improved.

\section{Statistical analysis}

We used the Wilcoxon test to compare DAS28-CRP, FIM, and HAQ-DI before and after surgery. Mann-Whitney U-test was used to compare these results among the different groups. Multiple regression analysis of change in FIM at 9 years after synovectomy was performed, and it included factors, such as rehabilitation, HAQ-DI at baseline, MTX dosage, PSL dosage, age, and gender. The p-values $<0.05$ were considered statistically significant.

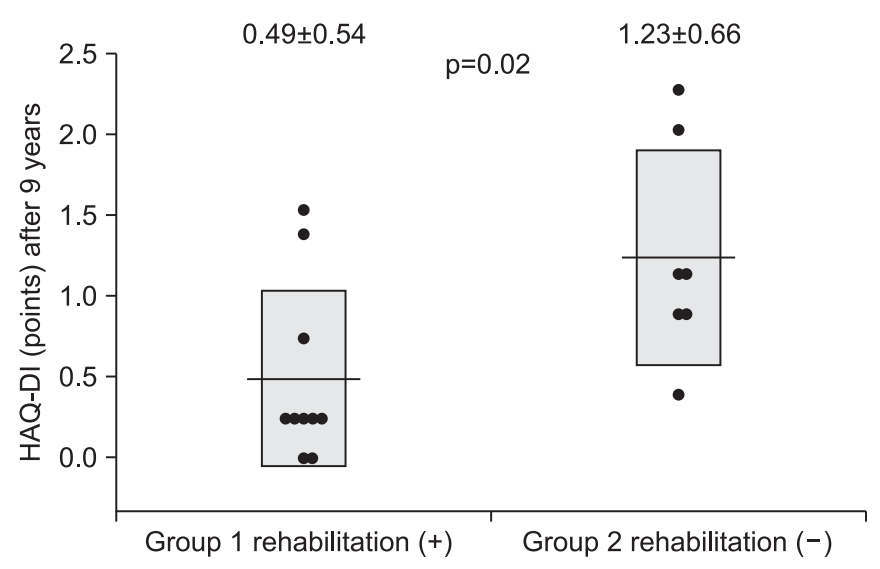

Fig. 2. Health Assessment Questionnaire-Disability Index (HAQ-DI) at 9 years after arthroscopic synovectomy with (group 1) or without (group 2) rehabilitation. 
Statistical analysis was performed using StatFlex version 6.0 (StatFlex, Tokyo, Japan).

\section{RESULTS}

Baseline clinical characteristics were not significantly different between group 1 (with rehabilitation) and group 2 (without rehabilitation). There were no complications and severe side effects after surgery in both groups. Stage and class of RA in both groups were not significantly different. The characteristics included age $(\mathrm{p}=0.12)$, percentage of female $(\mathrm{p}=0.78)$, disease duration $(\mathrm{p}=0.37)$, follow-up period $(\mathrm{p}=0.56)$, DAS28-CRP $(\mathrm{p}=0.75)$, HAQ-DI $(\mathrm{p}=0.33)$, and FIM $(\mathrm{p}=0.86)$ (Table 1$)$. The change in FIM was significantly increased in group $1(10.2 \pm 3.29)$ compared with group 2 at the 3 -month follow-up (7.00 \pm 1.91$)(p=0.04)$. The change in FIM was significantly increased in group $1(9.50 \pm 2.51)$ compared with group 2 at the 1 -year follow-up $(6.86 \pm 1.57)(\mathrm{p}=0.03)$. The change in FIM was significantly increased in group 1 $(9.00 \pm 1.89)$ compared with group 2 at the 9-year follow-

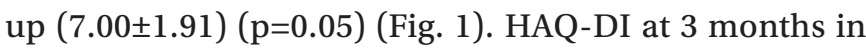
group $1(0.43 \pm 0.29)$ was significantly lower than that in group $2(1.23 \pm 0.66)(\mathrm{p}=0.004)$. HAQ-DI at 1 year in group $1(0.41 \pm 0.55)$ was significantly lower than that in group $2(1.09 \pm 0.60)(\mathrm{p}=0.03)$. HAQ-DI at 9 years in group 1 $(0.49 \pm 0.54)$ was significantly lower than that in group 2 $(1.23 \pm 0.66)(\mathrm{p}=0.02)$ (Fig. 2). Therefore, arthroscopic synovectomy with rehabilitation was significantly more effective according to the FIM score and HAQ-DI at the time

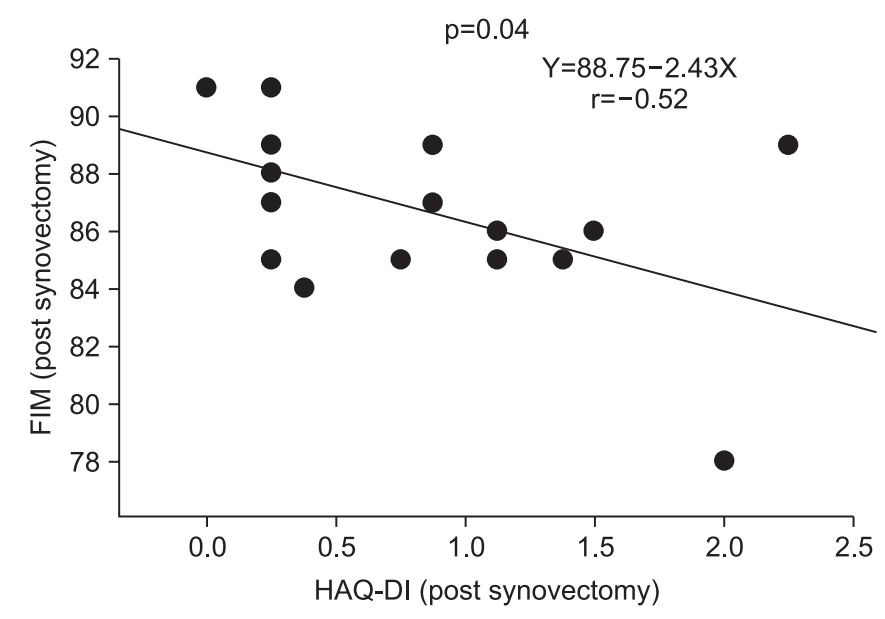

Fig. 3. The relationship between Functional Independence Measure (FIM) and Health Assessment QuestionnaireDisability Index (HAQ-DI) after arthroscopic synovectomy. of the long-term follow-up. Conversely, FIM score was significantly negatively correlated with HAQ-DI $(\mathrm{p}=0.04$, $\mathrm{r}=-0.52, \mathrm{Y}=88.75-2.43 \mathrm{X}$ ) (Fig. 3). Multiple regression analysis of FIM at 9 years revealed the effects of various factors; rehabilitation ( $p=0.03)$, disease duration $(p=0.02)$, HAQ-DI at baseline ( $p=0.75)$, MTX dosage $(p=0.88)$, PSL dosage $(\mathrm{p}=0.48)$, age $(\mathrm{p}=0.23)$, and gender $(\mathrm{p}=0.94)$ (Table 2). Thus, rehabilitation and short disease duration were significantly correlated with good outcomes following arthroscopic synovectomy in patients with RA at 9 years. FIM score at 9 years was significantly negatively correlated with disease duration $(\mathrm{p}=0.01, \mathrm{r}=-0.58$, $\mathrm{Y}=88.89-0.21 \mathrm{X}$ ) (Fig. 4). Therefore, early performance of arthroscopic synovectomy was important for obtaining a

Table 2. Multiple regression analysis of delta FIM at 9 years after synovectomy

\begin{tabular}{lc}
\hline \multicolumn{1}{c}{ Factor } & p-value \\
\hline Rehabilitation & $0.03^{*}$ \\
Disease duration & $0.02^{*}$ \\
HAQ-DI at baseline & 0.75 \\
MTX & 0.88 \\
PSL & 0.48 \\
Age & 0.23 \\
Gender & 0.94 \\
\hline
\end{tabular}

FIM, Functional Independence Measure; HAQ-DI, Health Assessment Questionnaire-Disability Index; MTX, methotrexate; PSL, prednisolone.

${ }^{*} \mathrm{p}<0.05$ were considered statistically significant.

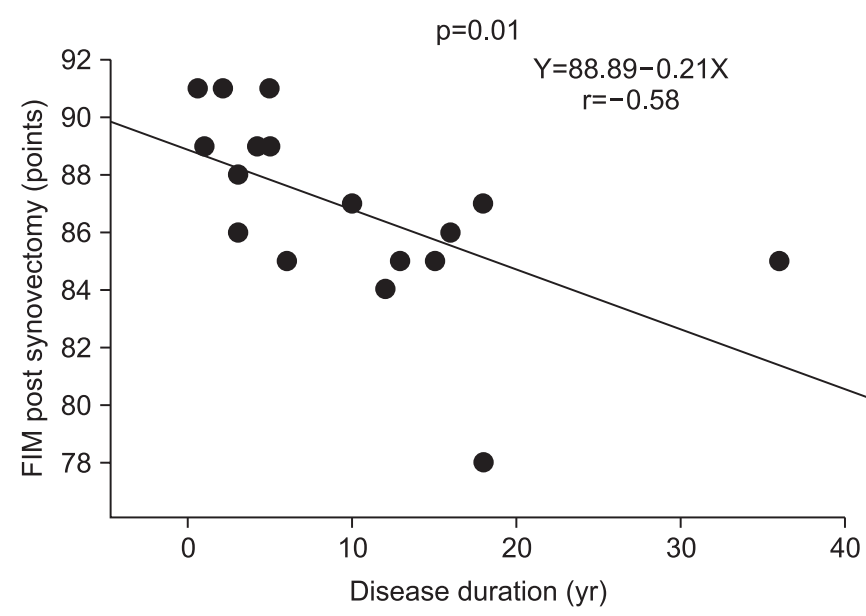

Fig. 4. The relationship between Functional Independence Measure (FIM) after arthroscopic synovectomy and disease duration. 
high FIM over a long period of time. A 26-year-old female with stage III and class 2 RA was treated at our clinic. Her disease persisted for 9 years and she was treated with $16 \mathrm{mg} /$ week MTX and $50 \mathrm{mg} /$ week etanercept. Her CRP level was $0.76 \mathrm{mg} / \mathrm{dL}$, DAS28-CRP was 2.95, matrix metalloproteinase (MMP) 3 level was $104 \mathrm{ng} / \mathrm{mL}$, serum TNF- $\alpha$ level was $17.7 \mathrm{pg} / \mathrm{mL}$, and IL-6 level was $2.6 \mathrm{pg} /$ $\mathrm{mL}$. She was suffering from severe RA-associated pain in her left shoulder. Radiographic examination showed severe bone destruction that resulted in an inability to perform activities of daily livings (Fig. 5A). She underwent arthroscopic synovectomy and rehabilitation before she could recover her ability to perform full forward flexion of the shoulder without pain. Arthroscopic findings showed synovial proliferation in the gleno-humeral joint of the right shoulder, and this proliferating synovium was removed using a shaver apparatus and radiofrequency
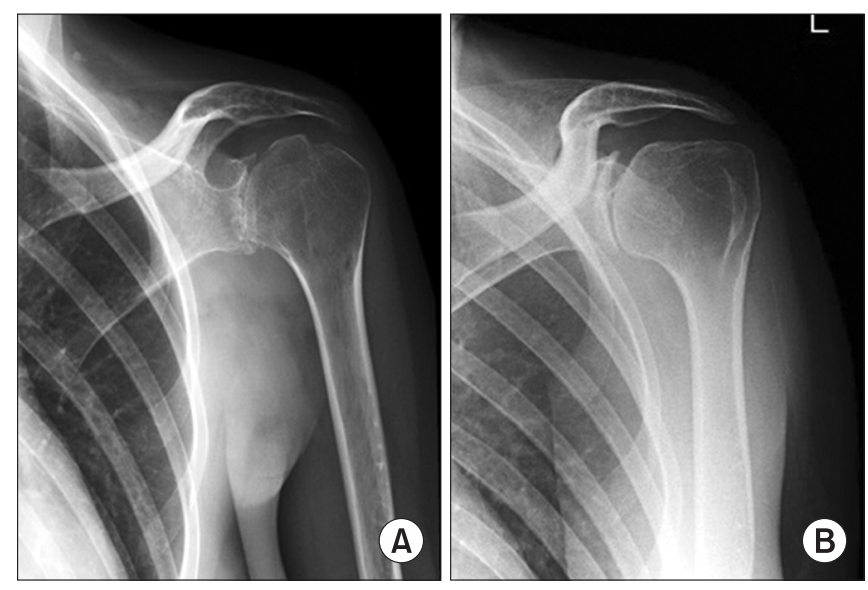

Fig. 5. An example of radiographic findings at baseline (A) and at 2 years after arthroscopic synovectomy with rehabilitation (B). device (VAPR; DePuy Synthes, West Chester, PA, USA) (Fig. 6A, 6B). Two years after arthroscopic synovectomy, the radiographic examination showed improvement in glenoid destruction, including a widened joint space and a visibly repaired glenoid surface (Fig. 5B).

\section{DISCUSSION}

Several reports have indicated that rehabilitation is effective in treating RA patients and in facilitating the recovery of functional ability that was lost following joint destruction and high disease activity $[18,19]$. However, the effects of combined surgical treatment and rehabilitation have not yet been analyzed, particularly in patients with RA over a long period. Brenda et al. [20] reported that early continued 2-3 week rehabilitation as soon as 48 hours after surgery was effective after synovectomy of the knee. We found a significant increase in FIM score and a decrease in HAQ-DI over 9 years in this study. Our findings demonstrate that rehabilitation after arthroscopic synovectomy continues to improve patient outcomes over a long period of time as opposed to those in patients who do not receive rehabilitation. We have previously reported that synovectomy decreases cytokine and chemokine production from the synovium, thereby reducing MMP-3 concentration and preventing cartilage destruction in patients with RA [21]. Rehabilitation may facilitate the recovery of muscle strength and improvement of joint ROM. Surprisingly, after more than 9 years, the effects of rehabilitation persisted when compared to RA patients who did not receive rehabilitation after arthroscopic synovectomy.

We identified two clinical factors that affected the long-term efficacy of arthroscopic synovectomy: reha-
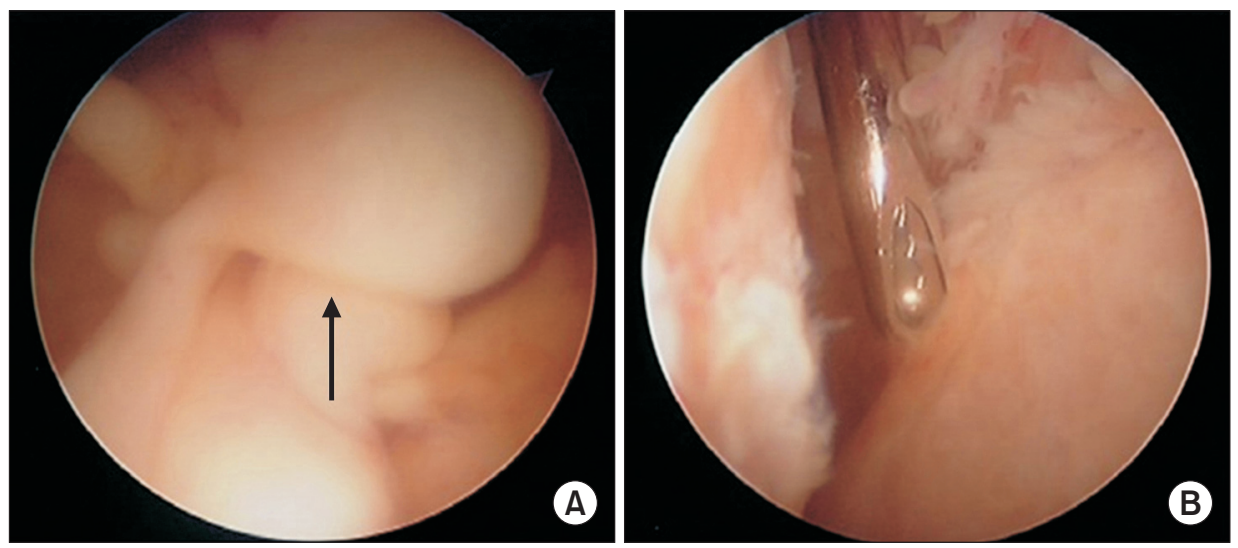

Fig. 6. An example of arthroscopic synovectomy. (A) Synovial proliferation (arrow) in the glenohumeral joint of the shoulder. (B) After synovectomy, during which the proliferating synovium was removed using a shaver apparatus. 
bilitation and disease duration. Therefore, it is critical to perform arthroscopic synovectomy and rehabilitation during the early stages of RA. Receiver operating characteristic (ROC) analysis showed that patients with a disease duration of 13 years or more would not benefit from arthroscopic synovectomy and rehabilitation (sensitivity $=87.5 \%$, specificity $=55.6 \%$, odds ratio $=8.75$ ). In this study, a 26-year-old patient with RA underwent arthroscopic synovectomy with rehabilitation. In her case, treatment resulted in a reduction in joint destruction, as indicated by the radiographic examination, at 2 years after the operation. This effect persisted over a long period of time and prevented the development of functional disability. It was possible to change the intraarticular environment using arthroscopic synovectomy and rehabilitation, which further facilitated the effects of MTX and other biologic treatments. This is the first report of long-term outcomes following arthroscopic synovectomy and rehabilitation. Our results should guide the routine treatment of RA, particularly in patients with early stage RA. The limitations of this study are as follows: this study was a retrospective case-control study. Therefore, arthroscopic synovectomy and rehabilitation were conducted at the discretion of patients. Furthermore, the number of patients was small, thus limiting our ability to draw significant conclusions. Accordingly, it was difficult to investigate the effect of rehabilitation in RA patients over a 9-year follow-up period with continuous medical treatment. Further investigations with more patients and multiple centers should be performed. In conclusion, this long-term, retrospective, case-control study indicates that rehabilitation following arthroscopic synovectomy was an effective method for the treatment of patients with RA.

\section{CONFLICT OF INTEREST}

No potential conflict of interest relevant to this article was reported.

\section{ACKNOWLEDGEMENTS}

This work was supported, in part, by a Grant-in-Aid for Scientific Research (KAKENHI) (C) (16K10920) from the Ministry of Education, Culture, Sports, Science and Technology and the Japan Society for the Promotion of
Science.

\section{REFERENCES}

1. Luqmani R, Hennell S, Estrach C, Basher D, Birrell F, Bosworth A, et al. British Society for Rheumatology and British Health Professionals in Rheumatology guideline for the management of rheumatoid arthritis (after the first 2 years). Rheumatology (Oxford) 2009; 48:436-9,

2. Forestier R, Andre-Vert J, Guillez P, Coudeyre E, Lefevre-Colau MM, Combe B, et al. Non-drug treatment (excluding surgery) in rheumatoid arthritis: clinical practice guidelines. Joint Bone Spine 2009;76:691-8.

3. Vliet Vlieland TP, Zwinderman AH, Vandenbroucke JP, Breedveld FC, Hazes JM. A randomized clinical trial of in-patient multidisciplinary treatment versus routine out-patient care in active rheumatoid arthritis. Br J Rheumatol 1996;35:475-82.

4. Jacobsson LT, Frithiof M, Olofsson Y, Runesson I, Strombeck B, Wikstrom I. Evaluation of a structured multidisciplinary day care program in rheumatoid arthritis. A similar effect in newly diagnosed and longstanding disease. Scand J Rheumatol 1998;27:117-24.

5. Tijhuis GJ, Zwinderman AH, Hazes JM, Breedveld FC, Vlieland PM. Two-year follow-up of a randomized controlled trial of a clinical nurse specialist intervention, inpatient, and day patient team care in rheumatoid arthritis. J Adv Nurs 2003;41:34-43.

6. Christie A, Jamtvedt G, Dahm KT, Moe RH, Haavardsholm EA, Hagen KB. Effectiveness of nonpharmacological and nonsurgical interventions for patients with rheumatoid arthritis: an overview of systematic reviews. Phys Ther 2007;87:1697-715.

7. Momsen AM, Rasmussen JO, Nielsen CV, Iversen MD, Lund H. Multidisciplinary team care in rehabilitation: an overview of reviews. J Rehabil Med 2012;44:901-12.

8. Lard LR, Visser H, Speyer I, vander Horst-Bruinsma IE, Zwinderman AH, Breedveld FC, et al. Early versus delayed treatment in patients with recent-onset rheumatoid arthritis: comparison of two cohorts who received different treatment strategies. Am J Med 2001; 111:446-51.

9. Landewe RB, Boers M, Verhoeven AC, Westhovens R, van de Laar MA, Markusse HM, et al. COBRA combination therapy in patients with early rheumatoid 
arthritis: long-term structural benefits of a brief intervention. Arthritis Rheum 2002;46:347-56.

10. Krishnan E, Fries JF. Reduction in long-term functional disability in rheumatoid arthritis from 1977 to 1998: a longitudinal study of 3035 patients. Am J Med 2003; 115:371-6.

11. Uhlig T, Kvien TK. Is rheumatoid arthritis really getting less severe? Nat Rev Rheumatol 2009;5:461-4.

12. Krishnan E, Lingala B, Bruce B, Fries JF. Disability in rheumatoid arthritis in the era of biological treatments. Ann Rheum Dis 2012;71:213-8.

13. Kanbe K, Inoue K. Efficacy of arthroscopic synovectomy for the effect attenuation cases of infliximab in rheumatoid arthritis. Clin Rheumatol 2006;25:877-81.

14. Arnett FC, Edworthy SM, Bloch DA, McShane DJ, Fries JF, Cooper NS, et al. The American Rheumatism Association 1987 revised criteria for the classification of rheumatoid arthritis. Arthritis Rheum 1988;31:31524.

15. Steinbrocker O, Traeger CH, Batterman RC. Therapeutic criteria in rheumatoid arthritis. J Am Med Assoc 1949;140:659-62.

16. Bruce B, Fries JF. The Health Assessment Questionnaire (HAQ). Clin Exp Rheumatol 2005;23(5 Suppl 39):S14-8.
17. Hamilton BB, Granger CV, Sherwin FS, Zielezny M, Tashman JS. A uniform national data system for medical rehabilitation. In: Fuhrer MJ, editor. Rehabilitation outcomes: analysis and measurement. Baltimore: Paul H. Brookes Publishing; 1987.

18. Meesters J, Verhoef J, Tijhuis G, Vliet Vlieland T. Functional disability in patients with rheumatoid arthritis admitted for multidisciplinary rehabilitation from 1992 to 2009. Rheumatology (Oxford) 2013;52:187983.

19. Klokkerud M, Hagen KB, Kjeken I, Bremander A, Horslev-Petersen K, Vlieland TV, et al. Development of a framework identifying domains and elements of importance for arthritis rehabilitation. J Rehabil Med 2012;44:406-13.

20. Brenda Z, Romanowski W, Bienkowski P, Lorenc R. Procedure for rehabilitation of the knee following synovectomy in patients with rheumatoid arthritis at the Poznan Rheumatological Center in Srema. Ortop Traumatol Rehabil 2000;2:74-7.

21. Kanbe K, Takemura T, Takeuchi K, Chen Q, Takagishi K, Inoue K. Synovectomy reduces stromal-cellderived factor-1 (SDF-1) which is involved in the destruction of cartilage in osteoarthritis and rheumatoid arthritis. J Bone Joint Surg Br 2004;86:296-300. 